\title{
Acta
Biochimica
Polonica
}

Vol. 47 No. 3/2000

$835-839$

QUARTERLY

\section{Densitometric quantification of DNA topoisomers in ethidium bromide-stained agarose gels and chemiluminescence-detected X ray films ${ }^{\boldsymbol{\theta}}$}

\author{
Zeki Topcu ${ }^{凶}$ \\ Department of Pharmaceutical Biotechnology, School of Pharmacy, Ege University, Izmir, Turkey
}

Received: 29 May, 2000; accepted: 12 June, 2000

Key words: DNA topoisomers, ethidium bromide, chemiluminescence, densitometry

This study investigates the contribution of deformational strain imposed by topological interconversions of DNA in ethidium bromide-binding on agarose gels. Closed-circular plasmid DNAs were nicked using UV exposure and the DNA bands were quantified by densitometry. The results show that the closed circular DNA binds the same amount of the dye as its nicked counterpart. The relationship between the band intensity on X-ray films of chemiluminescence-detected Southern blots and DNA concentration was shown to be linear.

Reliable quantification of DNA is an essential issue for researchers in biochemistry and molecular biology. Among the quantitative methods the assay of the intensity ultraviolet (UV)-induced fluorescence emitted by the intercalating dye, ethidium bromide (EtBr) is commonly applied. The dye is unaffected by the differences in the base composition and as little as 1 to $5 \mathrm{ng}$ of DNA can be estimated by this method [1]. However, topological interconversions impose a number of physical and chemical deformations on DNA molecules [2].
This study analyses whether there are any differences in binding of EtBr by closed-circular and UV-nicked circular DNAs.

Simultaneously, methods employing non-radioactive nucleic acid probes, such as chemiluminescence, became a fundamental approach in membrane (Southern, Northern, dot, slot blots, etc.) and in situ hybridization experiments [3]. Currently, major concerns are associated with the relationship between the band intensity and the amount of DNA in densitometric quantification of X-ray films

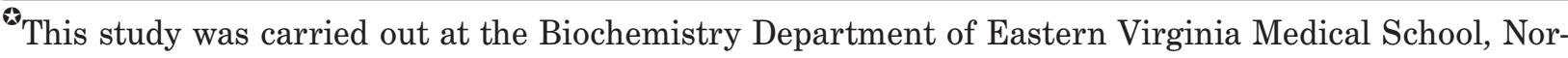
folk, VA, U.S.A.

${ }^{\otimes}$ Department of Pharmaceutical Biotechnology, School of Pharmacy, Ege University, 35100, Izmir, Turkey; Phone: (90 232) 388 4000/1931; Fax: (90 232) 388 5258; e-mail: ztopcu@bornova.ege.edu.tr Abbreviations: EtBr, ethidium bromide; mt topoI, mitochondrial type I DNA topoisomerase; DIG-dUTP, digoxigenin-labelled deoxyuridine triphosphate.
} 
analysed in chemiluminescence experiments. This study also investigates this relationship using assays of DNA supercoil relaxation catalysed by mitochondrial type I DNA topoisomerase (mt topoI).

\section{MATERIALS AND METHODS}

\section{Supercoil relaxation assays. DNA} topoisomerase I was isolated from calf liver mitochondria as described by Lazarus et al. [4]. Total enzyme concentration was estimated by the micro Bradford dye binding assay [5]. Supercoil relaxation was assayed in 40 $\mathrm{mM}$ Tris/ $\mathrm{HCl}(\mathrm{pH} \mathrm{7.0),} 60 \mathrm{mM} \mathrm{KCl}, 10 \mathrm{mM}$ $\mathrm{MgCl}_{2}, 0.5 \mathrm{mM}$ dithiothreitol (DTT), $0.5 \mathrm{mM}$ EDTA, $30 \mu \mathrm{g} / \mathrm{ml}$ bovine serum albumin (BSA) and indicated amounts of plasmid substrate, pUC19 $(2.69 \mathrm{~kb})$ in a total of $200 \mu \mathrm{l}$ final volume. Twenty microliter aliquots were removed and reactions were terminated by the addition of $3 \mu \mathrm{l}$ of $5 \%(\mathrm{w} / \mathrm{v})$ sodium dodecylsulfate (SDS) $/ 25 \%(\mathrm{w} / \mathrm{v})$ sucrose $/ 0.025 \%$ $(\mathrm{w} / \mathrm{v})$ bromophenol blue, and were applied on $0.8 \%$ agarose gel. One unit of enzyme activity is defined as that amount of enzyme which removes $50 \%$ of the supercoils from $300 \mathrm{ng}$ supercoiled pUC19 plasmid in $30 \mathrm{~min}$ at $37^{\circ} \mathrm{C}$ [4]. DNA bands from EtBr-stained $(1 \mathrm{mg} / \mathrm{ml})$ agarose gels $(0.8 \%)$ were photographed under UV illumination and relative amounts of supercoiled and relaxed DNA bands were determined by scaning photographic negatives with an Ultroscan XL Microdensitometer (LKB). Data from three independent experiments were averaged to produce values that represent the relative amounts of the different topological forms of DNA in each set. The differences in results between individual plasmid sets were analysed by Student's $t$-test (two-tailed) and the null hypothesis was rejected when $P<0.05$.

Chemiluminescence experiments. The chemiluminescence detection kit was purchased from Boehringer Mannheim Co. (Indianapolis, IN, U.S.A.). Plasmids were labelled by random-primed incorporation of digoxigenin-labelled deoxyuridine triphosphate (DIG-dUTP) as described previously [6]. Each reaction set containing varying amounts of labelled plasmids (from 0.1 to $2.0 \mu \mathrm{M}$ ) was incubated with eight units of $\mathrm{mt}$ topoI in $200 \mu \mathrm{l}$ final volume for $30 \mathrm{~min}$ at $37^{\circ} \mathrm{C}$. The reactions were terminated as above and applied on $0.8 \%$ agarose gel. DNA was transferred to nylon membrane by the capillary Southern-blotting procedure [1] and UV-linked with Stratalinker (Stratagene) at $1.2 \times 10^{3} \mathrm{Jm}^{-2}$ for $30 \mathrm{~s}$. The membrane was prehybridized for $1 \mathrm{~h}$ and relaxed DNA bands were visualized after hybridization of the membranes with DIG-labelled inserts under stringent conditions. Following autoradiography, the relative amount of supercoiled substrate converted to the relaxed form was determined by the formula: [1- $\left(s c_{0}\right.$ $\left.-s c_{t}\right) / s c_{0}$ ] where $s c_{0}$ and $s c_{t}$ stand for the areas under the peak of initial supercoiled DNA at zero time and the peak at time $t$, respectively. Bands were quantified by densitometric scanning of the films. All reagents were of analytical grade.

\section{RESULTS AND DISCUSSION}

A series of supercoil relaxation experiments were performed and the obtained products, separated by gel electrophoresis, were stained by EtBr and quantitated by using a densitometer. A representative gel is shown in Fig. 1. In each lane, the slower migrating band represents form-II or nicked-circular DNA while the fast migrating band represents form-I or supercoiled DNA. The ladder of bands between form-II and form-I DNAs are form-Ir, or partially relaxed circular DNAs generated by the removal of supercoils from highly supercoiled form I DNA by the action of $\mathrm{mt}$ topoI. As seen in Fig. 1, removal of the supercoils in pUC19 by the enzyme was consistent with the unit definition (see Materials and Methods). Densitometric quantification of the bands confirmed the expected distribu- 
tion of topologically different populations of plasmid DNA (isomers not shown).

Since the quantitative data were generated from the densitometric estimation in EtBr-stained DNA bands of relative amounts of plasmids with different topology, the influence of the nicks on EtBr-binding of plasmid

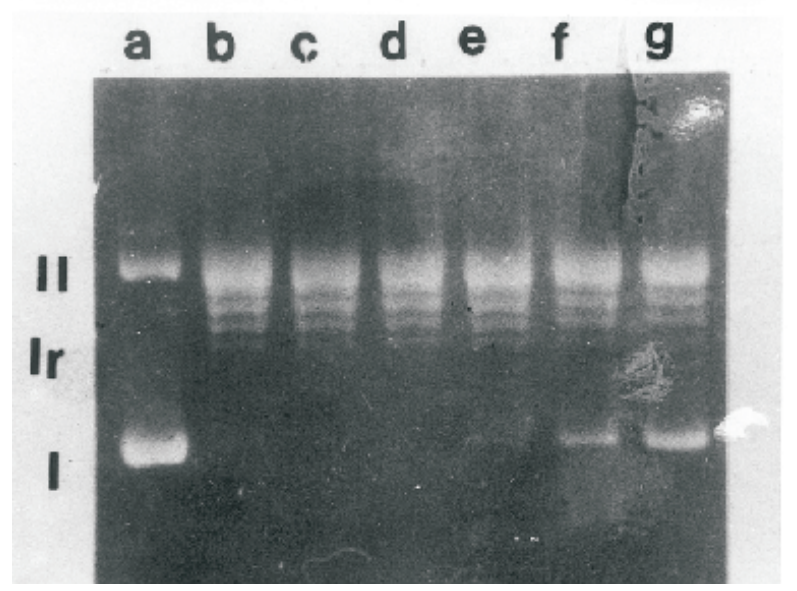

Figure 1. Agarose gel electrophoresis of mitochondrial type I topoisomerase ( $\mathrm{mt}$ topoI) relaxation assay.

pUC19 (300 ng) was incubated in each lane with 0 (lane a), 4 (lane b), 3 (lane c), 2 (lane d), 1 (lane e), 0.5 (lane f) and 0.25 (lane g) units of $\mathrm{mt}$ topoI in the reaction mixture as described in Materials and Methods.

DNA in agarose gels has been determined. This approach was first reported in an early study of Bauer \& Vinograd [7] who pointed to a difference in the intercalation of certain dyes among the DNA populations of topologically different isomers. Different amounts of pUC19 plasmid DNA (100 ng to $300 \mathrm{ng}$ ) were electrophoresed on a $0.8 \%$ agarose gel (Fig. 2). The gels were stained with $1 \mu \mathrm{g} / \mathrm{ml} \mathrm{EtBr}$, and photographed (Fig. 2 panel I), then DNA samples on the gel were UV-irradiated with $5.4 \times$ $10^{4} \mathrm{Jm}^{-2}$ to introduce a significant amount of nicks and $1.1 \times 10^{5} \mathrm{Jm}^{-2}$ to convert DNA into the completely nicked form [8] under illumination with short wave UV light before and rephotographed (Fig. 2, panels II and III, respectively). Thus, any change in band intensity would reflect the change in the EtBr-binding of nicked-circular DNA relative to closed-circular DNA. The average results of densitometric quantification from three independent measurements are summarized in Table 1 for relaxed DNA samples. Relative amounts of relaxed DNA are given in $\mathrm{A}_{260} \times$ area in $\mathrm{mm}^{2}$ for groups a (100 $\left.\mathrm{ng}\right), \mathrm{b}$ (200 ng) and c (300 ng) of pUC19 plasmid. As shown in Table 1, densitometric analyses revealed that

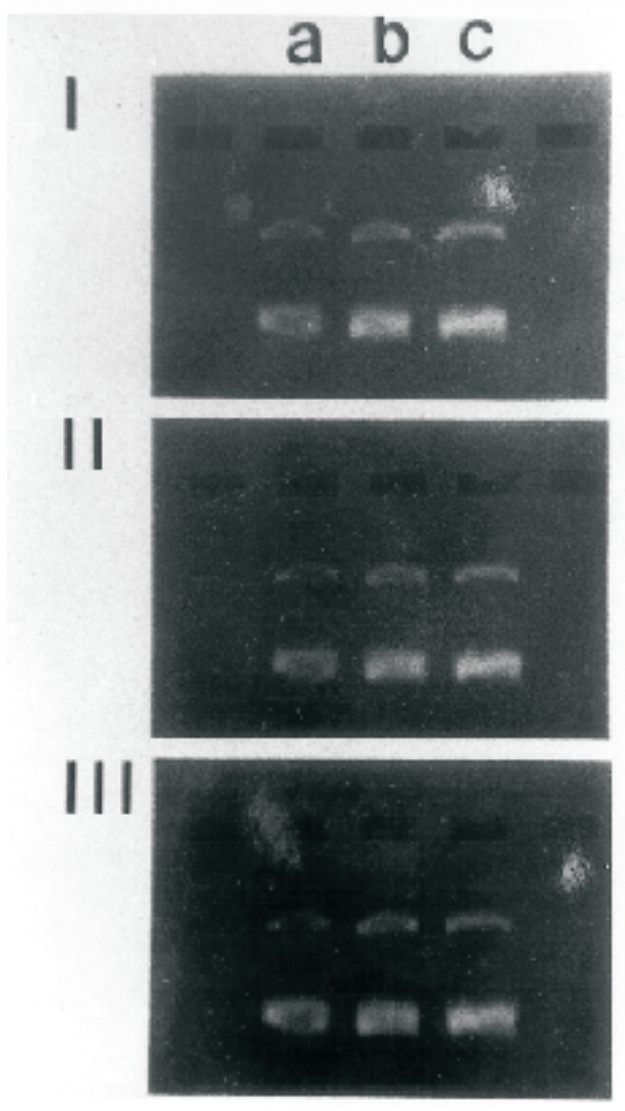

Figure 2. Comparison of relative amounts of EtBr binding by closed-circular and nicked circular forms of DNA.

pUC19 plasmid containing both superhelical form, $100 \mathrm{ng}$ (lane a), $200 \mathrm{ng}$ (lane b) and $300 \mathrm{ng}$ (lane c) was electrophoresed on a $0.8 \%$ agarose gel, stained with 1 $\mu \mathrm{g} / \mathrm{ml}$ ethidium bromide and photographed (panel I). The gel was irradiated with $5.4 \times 10^{4} \mathrm{Jm}^{-2}$ or $1.1 \times$ $10^{5} \mathrm{Jm}^{-2}$ by short wave UV light before being rephotographed (panels II and III, respectively).

the maximum difference between group-a and group-c prior to UV-exposure was 1.4-fold, indicating that the increase in the amount of DNA was not proportionally reflected in the estimated densities. However, this study concerns only the relative densities of the closed-circular and nicked-circular DNA popu- 
lations. The average relative densities of different UV-exposure groups, analysed vertically in Table 1 , show that the difference between either the control and $5.4 \times 10^{4} \mathrm{Jm}^{-2}$ group $(P=0.51)$ or the control and $1.1 \times 10^{5}$ $\mathrm{Jm}^{-2}$ group $(P=0.56)$ is not statistically sig-

Table 1. Densitometric quantification of the dye binding intensity of UV-irradiated plasmid pUC19 DNA samples

\begin{tabular}{lccc}
\hline $\begin{array}{l}\text { UV exposure } \\
\left(\mathrm{Jm}^{-2}\right)\end{array}$ & \multicolumn{3}{l}{$\begin{array}{l}\text { Supercoiled-DNA band intensity } \\
\left(\mathrm{A}_{260}\right) \times\left(\text { area in } \mathrm{mm}^{2}\right)\end{array}$} \\
\hline & $\mathrm{a}(100 \mathrm{ng})$ & $\mathrm{b}(200 \mathrm{ng})$ & $\mathrm{c}(300 \mathrm{ng})$ \\
Control & 3.09 & 3.66 & 4.47 \\
$5.4 \times 10^{4}$ & 3.72 & 4.34 & 4.03 \\
$1.1 \times 10^{5}$ & 3.47 & 3.38 & 4.82 \\
\hline
\end{tabular}

${ }^{*}$ See the text for statistical evaluation.

nificant. This indicates that, irrespective of the total amount of DNA, EtBr-binding to the relaxed form of DNA is not significantly influenced by the presence of nicks. A similar conclusion has been drawn for a supercoiled plasmid population (not shown) derived from the identical plasmid source and having equal initial relative amounts of supercoiled DNA as that used in the present experiments.

The relationship between the band intensity and the amount of DNA observed on densitometric quantification of X-ray films was also investigated using chemiluminescence. Varying amounts of plasmids labelled by DIG-dUTP were incubated with eight units of $\mathrm{mt}$ topoI and relative densities of the reaction products following hybridization of the membrane with DIG-labelled probes were quantified on X-ray films (Fig. 3). The densitometric band intensity increased with DNA concentrations showing a linear relationship $\left(\mathrm{r}^{2}=\right.$ $0.9250)$. The range of the substrate concentration, covered on the plot, was within the typical range of chemiluminesce studies [3].

Ethidium bromide contains a planar aromatic structure that can insert itself between two adjacent base pairs of DNA duplex [2]. In addition to its ability to significantly enhance fluorescence on DNA-binding, EtBr has an additional property interesting from the topological point of view, as it causes local winding of the helix [9]. The dye is unaffected by the differences in DNA base composition [1]. Our results also indicate that the presence of nicks in DNA does not influence EtBr-binding as nicked-circular DNA and closed-circular DNA bound $\mathrm{EtBr}$ in an analogous fashion under conditions of the experiments. Our study also reports a linear relationship between the densitometric intensities and DNA concentration on quantification of X-ray films of

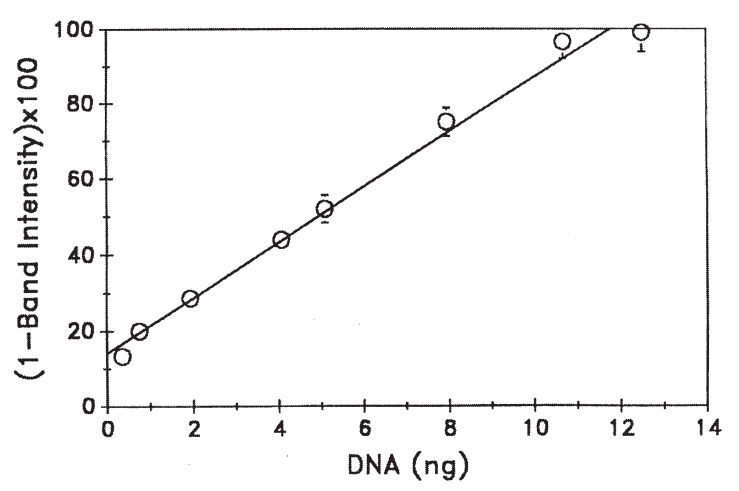

Figure 3. The relationship between the band intensity and amount of DNA on densitometric quantification of X-ray films of chemiluminescence-detected Southern blots.

The data points were obtained from three separate measurements $\left(r^{2}=0.93\right)$.

chemiluminescence-detected Southern blots. Determination of intrinsic EtBr-binding constants of DNAs with different superhelical densities in relation to the topological parameters, twist and writhe, is currently in progress.

The author acknowledges the valuable guidance by Dr. Frank J. Castora throughout the study. Thanks are also due to Dr. O. Sercan for his help in densitometric quantifications. 


\section{R E F E R E N C E S}

1. Ausubel, F.M., Brent, R., Kingston, R.E., Moore, D.M., Seidman, J.G. \& Struhl, K. (1987) Current Protocols in Molecular Biology; pp. 2.5.1-2.5.9, John Wiley and Sons Inc., New York.

2. Heath, P.J., Clendenning, J.B., Fujimoto, B.S. \& Schurr, J.M. (1996) Effect of bending strain on the torsion elastic constant of DNA. J. Mol. Biol. 260, 718-730.

3. Holtke, H.J., Ankenbauer, W., Mühleg, K., Rein, R., Sagner, G., Seibl, R. \& Walter, T. (1995) The digoxigenin (DIG) system for non-radioactive labelling and detection of nucleic acids - An overview. Cell. Mol. Biol. 41, 883-905.

4. Lazarus, G.M., Henrich, J.P., Kelly, W.G., Schmitz, S.A. \& Castora, F.J. (1987) Purification and characteristics of a type I topoisomerase from calf thymus mitochondria. Arch. Biochem. Biophys. 293, 201-207.
5. Bradford, M.M. (1976) A rapid and sensitive method for the quantitation of microgram quantities of protein utilizing the principle of protein-dye binding. Anal. Biochem. 72, 248-254.

6. Topcu, Z. \& Castora, F.J. (1995) Mammalian mitochondrial DNA topoisomerase I preferentially relaxes supercoils in plasmids containing specific mitochondrial DNA sequences. Biochim. Biophys. Acta 1264, 377-387.

7. Bauer, W. \& Vinograd, J. (1970) Interaction of closed circular DNA with intercalative dyes; the free energy of superhelix formation. Mol. Biol. 47, 419-435.

8. Oppenheim, A. (1981) Separation of closed circular DNA from linear DNA by electrophoresis in two dimensions in agarose gels. Nucleic Acids Res. 9, 6805-6812.

9. Bates, A.D. \& Maxwell, A. (1993) DNA Supercoiling; in DNA Topology (Rickwood, D., ed) pp. 17-45, IRL-Press Inc, New York. 